\title{
Preventing diseases in an urban scale
}

\author{
Tymon Dmochowski ${ }^{1, *}$ \\ ${ }^{1}$ Wrocław University of Science and Technology, Faculty of Architecture, Prusa 53/55, 50-317 \\ Wrocław, Poland
}

\begin{abstract}
A perfect setup to prevent epidemics is currently in affect throughout the world. Sanitary engineering, though not directly, is largely responsible for the annihilation of many diseases that used to be very problematic, such as typhus or cholera. However, these diseases are outdated and haven't been a problem for over a century due to the success of infrastructure such as water treatment and sewage. Modern causes of death (such as car accidents) are still overshadowed by the death toll taken up by illness. What is different is the nature of those diseases. In order to prevent them, on a larger scale, a new approach must be created. This paper offers an idea on how to return to the core of sanitary engineering and improve modern health conditions by exploring the etiology of these afflictions and providing precise engineering solutions.
\end{abstract}

\section{Problem - harmful urban systems}

In the most common perception of urban life, a city without infrastructure is unimaginable. Access to tap water, sewage, heating and gas systems is demanded in every household. The major influx of population from rural areas to cities, visible in the previous decades, heralds the continuous growth of urban areas and hence the demand for infrastructure. This goes in line with the population boom. At the beginning of the $20^{\text {th }}$ century, the world's population was only a fraction of the present, with about 1750000000 people, and has since increased over 4 times with current population being over 7600000000 . The year 2007 marks the moment when half of the world population already lived in cities, and this number is constantly growing [1].

In the light of these challenges, urban sanitary engineering has performed admirably. Epidemics that threatened Europe not so long ago like typhus, cholera or tuberculosis, which was one of the leading causes of death in the year 2011 [2], are nearly gone. When looking at the most recent data provided by the World Health Organization it is clear that the list has changed greatly and the leading causes of death are now heart diseases. Interestingly enough, according to the same fact sheet from 2011, WHO indicates the disparity between the low and high income countries, where ischemic heart disease is the leading cause of death in the latter. However, already in 2015, it has overshadowed other diseases by being the main cause of death globally (Tab. 1).

\footnotetext{
*Corresponding author: tymon.dmochowski@pwr.edu.pl
} 
Table 1. Top 10 causes of death globally in the year 2015,

based on: http://www.who.int/mediacentre/factsheets/fs310/en/

\begin{tabular}{|l|c|c|}
\hline \multicolumn{1}{|c|}{ Cause } & Deaths (millions) & \% of deaths globally \\
\hline Ischemic heart disease & 8,76 & 15,5 \\
\hline Stroke & 6,24 & 11,1 \\
\hline Lower respiratory infections & 3,19 & 5,7 \\
\hline Chronic obstructive pulmonary disease & 3,17 & 5,6 \\
\hline Tracheal, bronchial, lung cancers & 1,69 & 3,0 \\
\hline Diabetes mellitus & 1,59 & 2,8 \\
\hline Alzheimer, dementias & 1,54 & 2,7 \\
\hline Diarrheal diseases & 1,39 & 2,5 \\
\hline Tuberculosis & 1,37 & 2,4 \\
\hline Road injury & 1,34 & 2,4 \\
\hline
\end{tabular}

Ischemic heart disease along with stroke are a staggering cause of $26,6 \%$ of all deaths globally. Moreover, developed countries, where urban life is dominant, tend to be on the top of the list where the occurrence rate is high. In Poland, just in the year 2008, 79 thousand people died of Ischemic heart disease; in the United Kingdom - 92 thousand, in Germany - 155 thousand [3].

One of the major problems when tackling with this problem is the gap of knowledge between the true etiology of these diseases and what we know today. The research conducted on this matter clearly indicates a relationship between physical activity and health. Moreover, it is hinted, that regular exercise contributes to the overall well-being, which is significant for the healthy state of the heart [4 - 6]. This paper is an attempt to extend the expertise of urban sanitary engineering to use what knowledge we have and contribute to the prevention of modern diseases.

\section{Urban engineering as an existing solution}

The method of urban sanitary engineering has proven its effectiveness over the years as the most efficient way to combat epidemics. While looking for the roots of this method it would be prudent to remember the $19^{\text {th }}$ century epidemic of cholera in London. A person very active in that era was John Snow (1813-1858), who can be considered here as a forefather of epidemiology for several reasons. His approach to pursue the true cause of cholera (as it was widely considered to be spread by enigmatic miasma) was a decent attempt at etiological research. Secondly, his map of the spatial occurrence of disease can be considered as a major breakthrough in geographical medicine (Fig. 1). As we now know, this map allowed him to narrow down the cause of the epidemic to the water pump on Broad Street. The next step belonged exclusively to sanitary engineering as it was essential to provide clean water to this pump, one that came from the upper run of the Thames River and not the lower, where it was already polluted by the city.

The method presented in this chapter can be simplified to a basic flowchart (Fig. 2). When it comes to modern sanitary engineering, the focus is based solely on the last part. 
Because it tackles diseases and epidemics from the $19^{\text {th }}$ century, the research into the etiology is no longer needed. While it copes with outdated subjects it does not mean that it is redundant or that the method itself is outdated. On the contrary, it deals with the problems so efficiently that we no longer need to fear the spread of old epidemics.
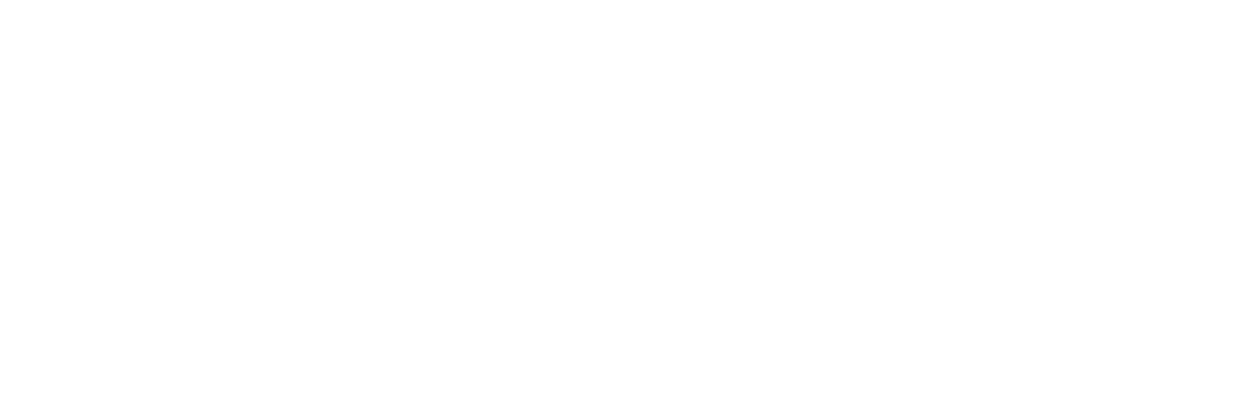

Fig. 1. Cholera infected hoseholds (black) in Soho, London 1854, created by John Snow source: https://pl.wikipedia.org/wiki/Plik:Snow-cholera-map-1.jpg

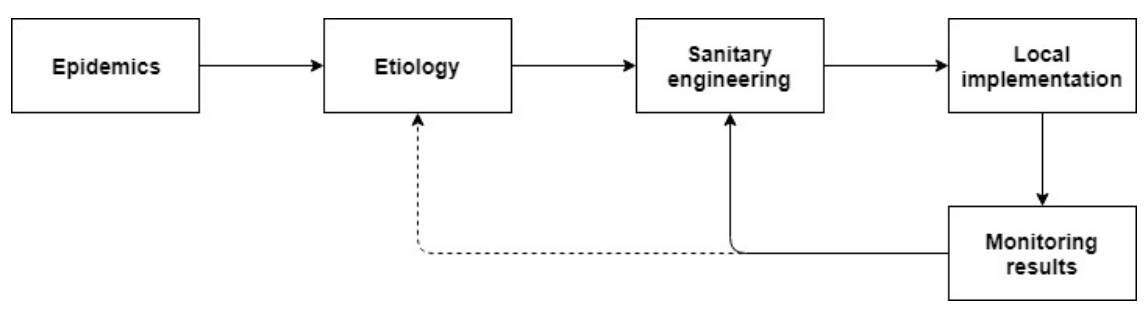

Fig. 2. Sanitary engineering flowchart.

However, the challenges of the modern world have shifted greatly, and the base of most dangerous diseases should be updated. The reality we face today, hopefully made clear in chapter 1, shows that the area of our focus should move towards different diseases. This shift was noted as far back as 1985, when diseases of industrial workers were an important issue. However this only gave birth to etiological research in a working environment [8]. The problem now lies in the fact, that in order to implement the method presented above, it 
is crucial to conduct massive scale research over the etiology of the main causes of death. However, this is not an excuse for an engineer to rest idly, as the important set of relations (between health and built environment) is already forming (Fig. 3).

\section{Biocenose}

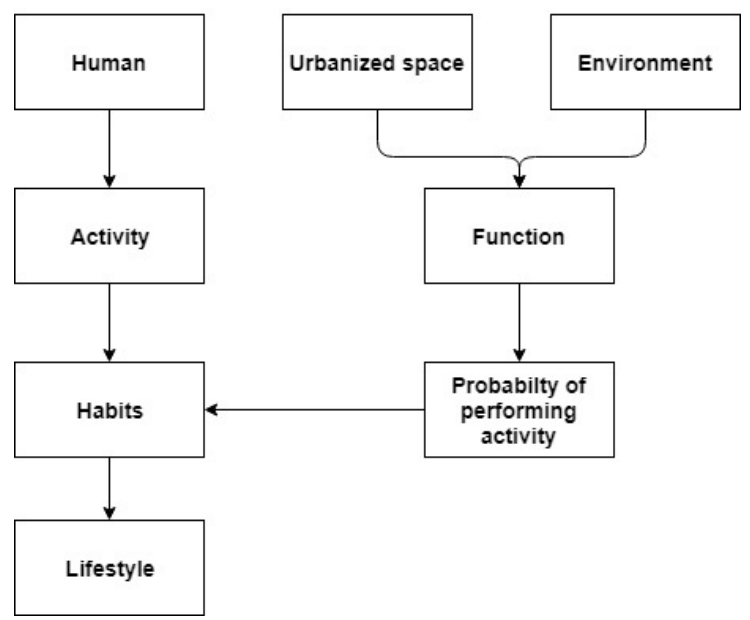

Fig. 3. Relationship of lifestyle, health and build environment.
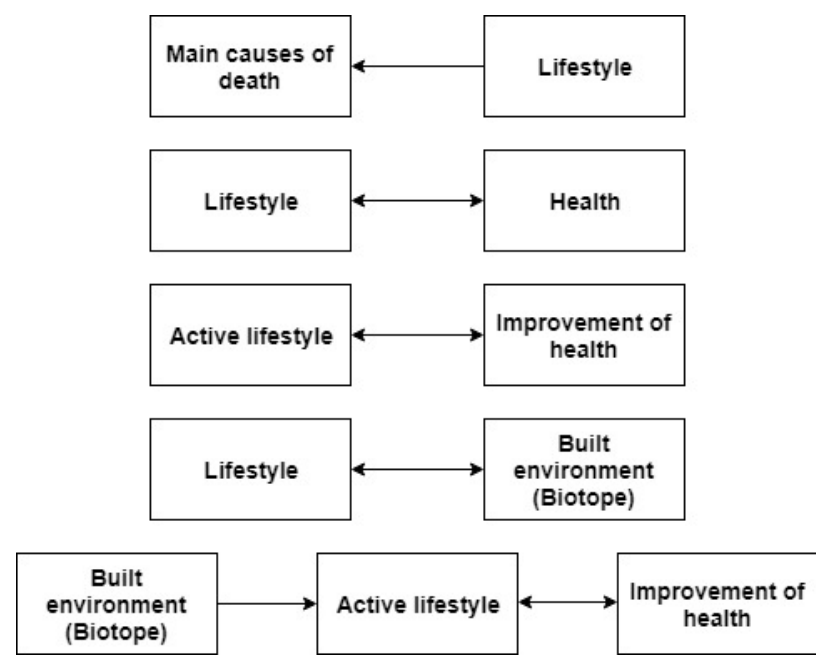

Fig. 4. Constructing a habit.

This leads to the crucial observation that attaching only one of two relationships (active lifestyle or built environment) to the improvement of health might not be enough. Often we are faced with the term "healthy city", but it is not the impact of the built environment itself that contributes to our health. Using another simple biological set of relationships between biotope (city) and biocenose (human), it is easy to note that the component of activity is the connector between them (Fig. 4). Only by creating space, that increases the probability of performing physical activity, can we expect results. Not only that, but in order to achieve a meaningful health improvement it is crucial to develop a habit that will continuously engage people in the said activity. Any attempt to deal with modern epidemics must take this into consideration. In short, create not a healthy space, but a space that increases the 
probability of performing an activity, and hence contribute to the development of a habit that might improve overall well-being. The positive health impact of greenery, that is crucial in the design of recreational spaces cannot be ignored either [7].

\section{Outlook of the new system}

In order to bring this theoretical model to life, the first thing to do is to create an efficient transfer of knowledge between planners, engineers and medical institutions. Urban planning lies in a niche where the transfer of knowledge is inefficient. In this case, an architect and civil engineer can serve as a striking contrast, as their knowledge seems almost inseparable. Interestingly enough, ergonomics is also crucial to the architectural level of development. What planning needs is exactly the same level of cooperation, but with medical and psychological institutions. The first benefit comes in the form of completing the flowchart from figure 2. Without etiological research from the medical side, and monitoring (if physical activity actually brings results in patient treatment) it is impossible to adjust local implementations accordingly. Another matter is, that despite the fact that the impact of activity over health has been proven, it is unclear what kind of activity, performed how often and in what kind of environment is beneficial. Perhaps the use of a treadmill in a closed, sweaty, fungus-infused air of a fitness center is not equal in benefit to a simple walk in a properly created recreational space. Regardless of the subjective feeling about this, such a relation has not been properly researched. If we simplify this subject to the case of ergonomics, any chair design can verify its health impact on the end user, using the "model" provided by an orthopedist. Such parameters should be created for public spaces - a model that answers the question if the specific public space is healthy.

Another matter, is that blindly creating recreational spaces, might not be efficient in an entire urban scale. It is unreasonable and most likely impossible due to financial limitations, to implement proper recreational paths everywhere. Here lies another challenge for the medical sector - the creation of maps of the spatial occurrence of diseases. In order to bring readers closer to this subject, I'd like to firstly refer them to the second chapter (Fig. 1) and secondly, present a map of neoplasm occurrence in the Lower Silesia region of Poland (Fig. 5).

I would like it to serve as both a good and bad example. Good - because if such maps could be made for a city scale, with districts or even neighborhoods as base units, it would finally be possible to identify the "unhealthy" parts of the city. Such data pinpointing to, for example, districts plagued by cardiovascular diseases, might serve as a good indicator that engineering intervention is required. But I'd like it to serve as a bad example as well, as this map, in its current form, is utterly useless. The reason why is explained in previous chapters. Neoplasm has countless variations, and each of these variations has a different cause. Hence, from an etiological point of view, it would be wrong to come up with conclusions for a specific municipality based solely on the number of neoplasm occurrences. The data needed for such maps has to greatly emphasize the cause behind the disease and categorize data accordingly. It is a good moment to mention, that in some cases, despite the best and most sincere efforts to prevent certain diseases, the genetic predispositions of an individual, may be the main and so far unavoidable cause. Those cases should not contribute to the overall data.

Lastly, any attempt to incorporate this system would require project management at the city level, with every local implementation contributing to the realization of a main, citywide objective - reducing the number of people falling ill to modern diseases. The observable fashion, for social engagement in the urban quality of life improvement, can serve here as a beneficial factor. If a proper measurable, achievable and time-bound health 
parameter can be attributed to every project of public space, then it would be possible to remove the negative political and subjective artistic decision-making aspect of city planning. The last word would then belong to the engineer who, in light of such a parameter, can compare two projects of public space and unequivocally chose one that fulfills its main objective.

\section{Neoplasm occurance in Lower Silesia Voivodeship 2015}

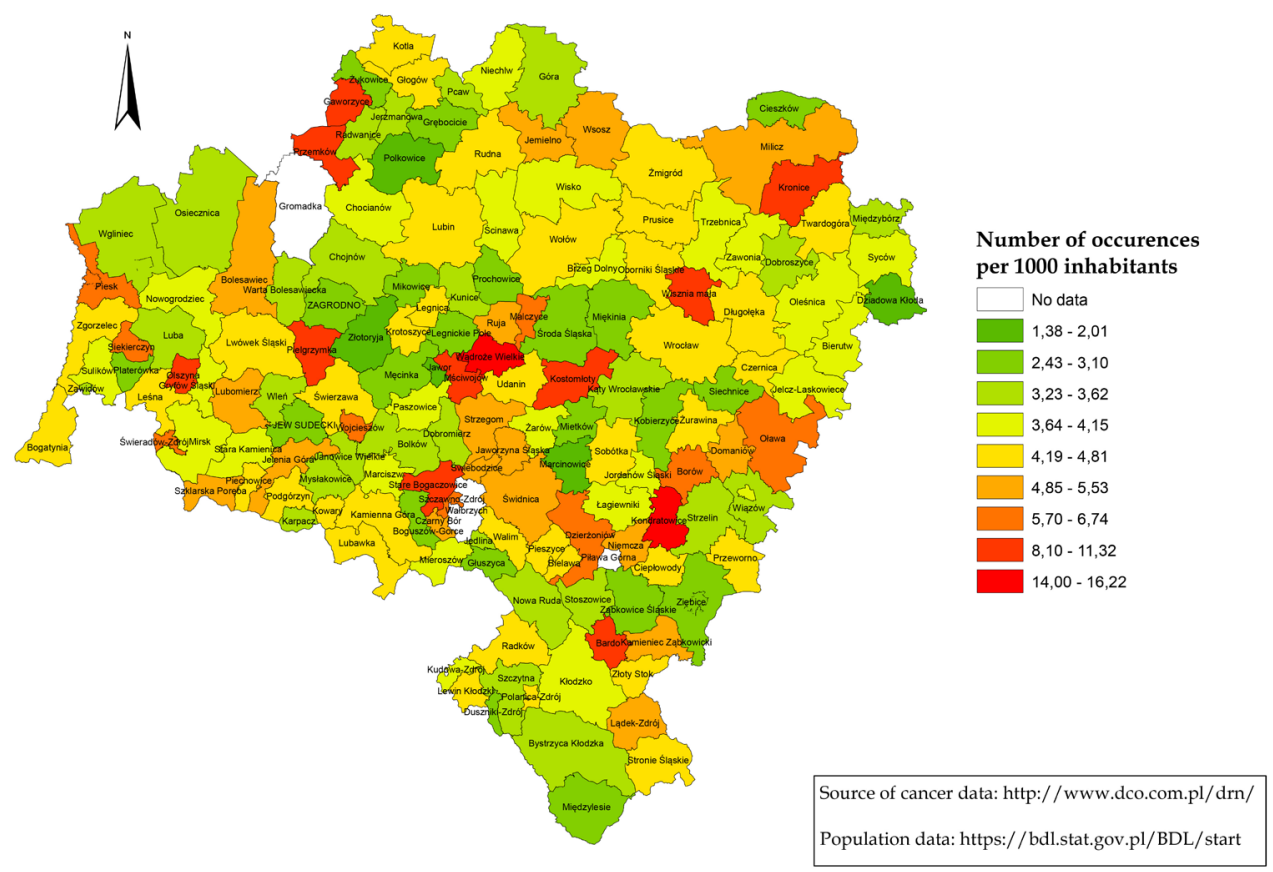

Fig. 5. Miniature of a map representing neoplasm occurance in Lower Silesia in 2015.

\section{Conclusions}

While faced with modern day diseases, it is hard to deny, that the amount of heart disease cases have reached a point of epidemic. The cost of treating a single patient, diagnosed with ischemic heart disease or recovering from a stroke, compared with the possible beneficial impact of recreational systems, encourages the exploration of possibilities. The system presented in this work tackles the problem by indicating that the solution already exists and a method of sanitary engineering can be extended to cover the problem of modern diseases. With extended medical research over the etiology it is possible to create urban recreation systems that will treat, and in many cases prevent, illness.

Perhaps the most important challenges lie in the creation of a health parameter. Such an indicator could be a powerful tool to rationalize the evaluation of public space projects. Moreover it might become a key feature in massive urban developments, like a new housing district, serving both the developer and potential customer.

Implementing such a system, while greatly beneficial, is not devoid of problems. Its nature prevents it from being used for a business model, other than the previously mentioned massive scale housing developments. This means that the creation, improvement or rearrangement of public spaces would have to be financed from public coffers. Its chance for success lies in the growing public awareness and massive social and non-governmental support. 
Table 2. SWOT analysis of the presented system.

\begin{tabular}{|c|c|}
\hline Strengths & Weaknesses \\
\hline $\begin{array}{l}\text { - Uses the existing method of } \\
\text { preventing epidemics that is } \\
\text { proven to be efficient. } \\
\text { - Provides verifiable results. } \\
\text { - Has potential to prevent disease on a } \\
\text { massive scale. } \\
\text { - Enhances interdisciplinary } \\
\text { cooperation. }\end{array}$ & $\begin{array}{l}\text { - Very low amount of data. } \\
\text { - Etiology of the main causes of death is } \\
\text { not properly researched. } \\
\text { - Requires new system of knowledge } \\
\text { transfer. }\end{array}$ \\
\hline Opportunities & Threats \\
\hline $\begin{array}{l}\text { - A chance to gain large and growing } \\
\text { social support due to measureable } \\
\text { parameter of health for public } \\
\text { spaces. } \\
\text { - Removing political and artistic aspect } \\
\text { from decision-making process in } \\
\text { the design of public spaces. } \\
\text { - Creation of a tool for the comparison } \\
\text { of public space projects. }\end{array}$ & $\begin{array}{l}\text { - No medical or other specialization that } \\
\text { would develop this subject. } \\
\text { - Presented variant of this system is hard } \\
\text { to monetize. No business can gain } \\
\text { profit from its development. } \\
\text { - Efficient prevention systems are a } \\
\text { financial danger for pharmaceutical } \\
\text { companies. }\end{array}$ \\
\hline
\end{tabular}

In order to evaluate the presented system, one must first be aware of the fact that this is a specific variant, one that mainly focuses on the beneficial aspect of physical activity on the main and modern causes of death. However, the benefits of activity can contribute to solving a series of modern day problems. Urban planning, in its recent chaos is often experimental and tests its hypothesis directly on humans. A system that implements modeled, tailored and proved solutions can contribute greatly to the quality of space and hence the quality of life. It stands as an engineer's answer to "fashionable" ideas of a human-scale or "walkable" city presented by figures such as J. Jacobs, J. Ghel or even K. Lynch.

I would like to extend my gratitude towards Professor Tadeusz Zipser, from the Urban Cybernetics Laboratory (Laboratorium Cybernetyki Urbanistycznej przy Politechnice Wrocławskiej) and Maciej Szarejko Ph.D., from the Quality of Life Cybernetics Laboratory (Laboratorium Cybernetyki Jakości Życia przy Politechnice Wrocławskiej), who both offered me substantial help and a critical review of my work.

\section{References}

1. T. Zipser, Architectus Prediction of states, modelling of processes and building the decisions 47, 3-13 (2016)

http://www.architectus.arch.pwr.wroc.p1/47/47_01.pdf

2. World Health Organization, Fact Sheet The top ten causes of death (2011)

http://www.who.int/mediacentre/factsheets/fs310_2008.pdf

3. J. A. Finegold, P. Asaria, D. P. Francis, International Journal of Cardiology Mortality from ischaemic heart disease by country, region, and age: Statistics from World Health Organisation and United Nations 168, 934-945 (2013)

http://www.internationaljournalofcardiology.com/article/S0167-5273(12)01421-0/pdf

4. S. N. Blair, J. N. Morris, Ann Epidemiol Healthy Hearts-and the Universal Benefits of Being Physically Active: Physical Activity and Health 19, 253-256 (2009) 
https://www.sciencedirect.com/science/article/pii/S1047279709000350

5. J. N. Morris, M. D. Crawford, British Medical Journal Coronary heart disease and physical activity of work 5111, 1496-1485 (1958)

https://www.ncbi.nlm.nih.gov/pmc/articles/PMC2027542/pdf/brmedj03082-0009.pdf

6. R. S. Paffenbarger, W. E. Hale, The New England Journal of Medicine, Work activity and coronary heart mortality 292, 545-550 (1975)

http://www.nejm.org/doi/full/10.1056/NEJM197503132921101

7. J. Mowszowicz, Problemy, Zieleń wydłuża życie 462, 2-4 (1985)

(Translated from Polish: Greenery extends life)

8. L. Grzegorczyk, Problemy, Cywilizacja a choroby skóry 467, 17-20 (1985)

(Translated from Polish: Civilization and skin diseases) 